\title{
UMA VISÃO SOBRE A EDUCAÇÃO AMBIENTAL EM ESCOLAS PÚBLICAS E PARTICULARES DA CIDADE DE MANAUS
}

Samanta Gabriela Souza da Silva ${ }^{1}$

Laura Graciliana Bernardes ${ }^{2}$

Resumo: No Brasil, a Constituição Federal de 1988, explícita que temos direito a um ambiente saudável, e que a Educação Ambiental (E.A.) ocorra em todos os níveis de ensino. Com o intuito de avaliar a situação da Educação Ambiental na cidade de Manaus (AM) realizou-se um estudo nas escolas públicas e particulares, utilizando questionários com perguntas fechadas. Os resultados mostram a existência de Educação Ambiental nas escolas de Manaus: 53\% escolas particulares, $50 \%$ escolas estaduais e $72 \%$ escolas municipais. Notase um crescente esforço em integrar a Educação Ambiental no processo de formação dos alunos, a fim de torná-los capazes de interferir positivamente no meio que os cercam.

Palavras-chave: Constituição; Educação Ambiental; Escolas.

${ }^{1}$ Faculdade Estácio do Amazonas. E-mail: samantasouzas@gmail.com

${ }^{2}$ Mestre em Ciências Ambientais e Florestais. Universidade Federal do Amazonas. E-mail: laurabernardes01@gmail.com. 


\title{
Introdução
}

Educação ambiental definida no Congresso de Belgrado promovido pela UNESCO em 1975, diz que trata se de um processo que visa:

[...] formar uma população mundial consciente e preocupada com o ambiente e com os problemas que lhe dizem respeito, uma população que tenha os conhecimentos, as competências, o estado de espírito, as motivações e o sentido de participação e engajamento que lhe permita trabalhar individualmente e coletivamente para resolver os problemas atuais e impedir que se repitam [...]. (UNESCO, 1975).

\begin{abstract}
Outra definição de educação ambiental é dada no artigo $1^{\circ}$ da Lei $n^{\circ}$ 9.795/99 como:

os processos por meio dos quais o indivíduo e a coletividade constroem valores sociais, conhecimentos, habilidades, atitudes, e competências voltadas para a conservação do meio ambiente, bem como uso comum do povo, essencial à sadia qualidade de vida e sua sustentabilidade. (BRASIL, 1999).
\end{abstract}

De acordo com a Constituição Federal de 5 de outubro de 1988, no Capítulo VI-Do meio ambiente, art. 225 diz que "Todos têm direito ao meio ambiente ecologicamente equilibrado, bem como de uso comum do povo e essencial à sadia qualidade de vida, impondo-se ao Poder Público e à coletividade o dever de defende-lo e preservá-lo para as presentes e futuras gerações" (BRASIL, 1988, p.114).

Tendo em vista estes conceitos a respeito de educação ambiental e a sua relevância perante a Constituição Federal, pode-se afirmar que todos os esforços atualmente implementados para que o repasse de informação seja a nível mundial, nacional ou local partem de pensamentos, anseios e atitudes criados ao longo dos anos para tentar minimizar efeitos de atividades poluidoras que acumularam-se durante a caminhada da civilização.

Durante a evolução humana, o homem utilizou os recursos advindos da natureza e com o passar do tempo, notou que estes recursos não eram infinitos e então logo começou a preocupar - se com o futuro e com sua sobrevivência. Partindo deste preceito, surgiram manifestações que continham em seu contexto a preocupação ambiental.

Ao longo das décadas, várias instituições governamentais e não governamentais, pessoas físicas e jurídicas e governos - generalizando, a sociedade - interviu positivamente para que a preservação ambiental fizesse parte do cotidiano não somente escolar, mas também a nível de governamental com políticas que garantissem o desenvolvimento sustentável. 
Com as pressões políticas, sociais, econômicas e ambientais os governos necessitaram adequar-se as reivindicações feitas pela sociedade. Criaram todos os aparatos necessários para a inserção dos valores ambientais no cerne escolar. Diante dessas situações, o Brasil também se inseriu no eixo dos países que valorizaram o pensamento e a preocupação ambiental, incluiu em sua Constituição princípios voltados ao meio ambiente, dividiu atribuições ao Poder Público e permitiu que a educação ambiental fizesse parte do cotidiano escolar de todo o País. Com esse embasamento constitucional os munícipios puderam atuar em torno de direcionamento das políticas ambientais. Na Região Amazônica, especialmente em Manaus, o público alvo desta pesquisa de educação ambiental, ou seja, as escolas das redes públicas e particulares convivem diariamente com situações que levantam a temática do pensamento ambiental.

Por ser uma região onde encontra se a maior floresta tropical e o maior rio do mundo, as atenções em torno da preservação ambiental são um foco global. Mediante esse pensamento, a pesquisa deste trabalho torna se justificável pelo fato de poder avaliar quantitativamente a inserção da educação ambiental nas escolas da cidade de Manaus. Objetivando-se avaliar a promoção da educação ambiental nas escolas públicas e particulares da cidade de Manaus, assim como comparar os resultados obtidos de acordo com o perfil das escolas divididas em: públicas municipais, estaduais e particulares.

\section{Metodologia}

\section{Área de estudo}

O presente trabalho realizou se no estado do Amazonas (AM) pertencente à região Norte, cuja capital Manaus (03 $06^{\prime} 07^{\prime \prime} \mathrm{S}$ e $60^{\circ} 01^{\prime} 30^{\prime \prime} \mathrm{W}$ ) é o campo de estudo. De acordo com dados do Portal do Governo do Estado do Amazonas o estado possui uma área territorial de aproximadamente 1.559.161,682 KMㄹ e uma população de 3.483,985 habitantes, sendo 2.755,490 na área urbana e 728.495 na área rural. Em Manaus, a cidade mais populosa do estado, possui uma área de $11.458,5 \mathrm{KM}^{2}$ e população de $1.802,525$ habitantes, dentre os quais encontram se o público alvo do estudo: as escolas de redes públicas e particulares, com aproximadamente 590.000 alunos, de acordo com dados do IBGE (2010), SEDUC, SEMED e Sindicato dos estabelecimentos particulares de ensino do Amazonas.

\section{Coleta de dados}

A coleta de dados realizou se em um período de três (03) anos, 2012 a 2014 em escolas da rede pública subdivididas em estaduais e municipais e rede particular de ensino, totalizando-se 228 escolas e aproximadamente 203.549 estudantes, não foram analisados tamanho ou estrutura das unidades de ensino.

A rede pública estadual foi representada por 110 escolas (48\% do total 
rede pública municipal foi representada por 82 escolas $(20,7 \%$ do total de 396 escolas) totalizando 56.598 alunos e rede particular com 36 escolas (35\% do total de 126 escolas particulares) representando 20.985 alunos.

As instituições foram escolhidas aleatoriamente na cidade de Manaus, os dados analisados foram obtidos por meio de questionário contendo as seguintes perguntas: Nome da Escola, tipo de escola (particular, estadual ou municipal), endereço, quantidade de alunos, turnos, se a escola possui projetos de educação ambiental (sim ou não) e se sim, quais são os projetos. Aplicou-se o questionário aos responsáveis das escolas.

\section{Análise dos dados}

Com as informações obtidas foram feitas análises quantitativas. $O$ processo de análise dos dados realizou-se através do sistema Microsoft utilizando o software Excel que permite criar tabelas e gráficos, calcular e analisar dados. (MICROSOFT, 2010).

Avaliaram-se os dados e comparou-se entre escolas públicas: estaduais e municipais e particulares utilizando como cálculo base o sistema de porcentagem (\%) e expressando os resultados em formato de gráficos.

As informações extraídas foram organizadas em planilhas que foram tabuladas em escolas estaduais, municipais e particulares contendo as seguintes colunas: nome da escola, zona/bairro, nome do projeto (se houver), número de alunos. Quanto à existência ou ausência de projetos de educação ambientais, os resultados basearam-se apenas nas respostas concedidas pelos responsáveis em responder ao questionário.

\section{Resultados e discussões}

A educação ambiental em Manaus aponta um nível equilibrado, no Gráfico 1 verifica-se 58\% equivalente a 133 escolas com E.A. e $42 \%$ correspondente a 95 escolas que não possuem educação ambiental.

Gráfico 1: Total de escolas que possuem e não possuem educação ambiental. EDUCAÇÃO AMBIENTAL NAS ESCOLAS DE MANAUS

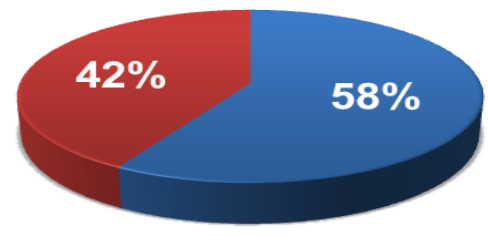

-POSSUEM E.A.

-NÃO POSSUEM E.A.

Fonte: A própria autora. 
O resultado apontado acima traz à tona o grau de promoção da educação ambiental em Manaus, nota se uma leve inclinação em relação às escolas que possuem educação ambiental. Um projeto de pesquisa feito pelo MEC, entre os anos de 2001 a 2004, intitulado "O que fazem as escolas que dizem que fazem Educação Ambiental?" explicita a realidade escolar. Segundo a pesquisa, o processo de Educação Ambiental foi bastante acelerado principalmente nas regiões Norte e Nordeste, sendo que nas regiões Sul, Sudeste e Centro Oeste o processo de inserção de temáticas ambientais já ocorria há tempos. De acordo com o Censo Escolar aplicam se três tipos de modalidades principais: projetos, disciplinas especiais e inserção da temática ambiental nas disciplinas. Apesar de todos os esforços que as escolas têm tido em relação à preocupação ambiental, percebe se que existem obstáculos que precisam ser transpassados para que obtenha se uniformidade na promoção da Educação Ambiental. De acordo com Medina (2001,p. 18) "[...] a essas dificuldades acrescentam-se as formas muitas vezes simplistas com que tem sido concebida e aplicada a Educação Ambiental [...]". Em 2009, SilvaForsberg, Mendes e Almeida publicaram um artigo relatando déficits dos professores em relação à Educação Ambiental em escolas públicas de Manaus, apontou-se a precariedade na formação dos professores de ciências relacionadas a cursos mal conceituados e falta de preparo adequado especialmente no que tange a educação continuada. Os resultados obtidos demonstram que necessitamos de um esforço para aumentar os índices educacionais relacionados à Educação Ambiental e que parte desse trabalho deve ser investido na valorização e motivação do professor, pois ele é o principal agente transformador e a ele cabe o dever de ensinar, estimular e formar cidadãos críticos.

Quando analisamos somente as escolas particulares temos no Gráfico 2 indicadores que mostram-se equilibrados com um total 36 instituições avaliadas sendo que 19 escolas alegam possuir trabalhos de educação ambiental (47\%) e 17 escolas afirmam que não possuem atividades voltadas a educação ambiental (53\%).

Gráfico 2: Escolas particulares que possuem e não possuem educação ambiental.

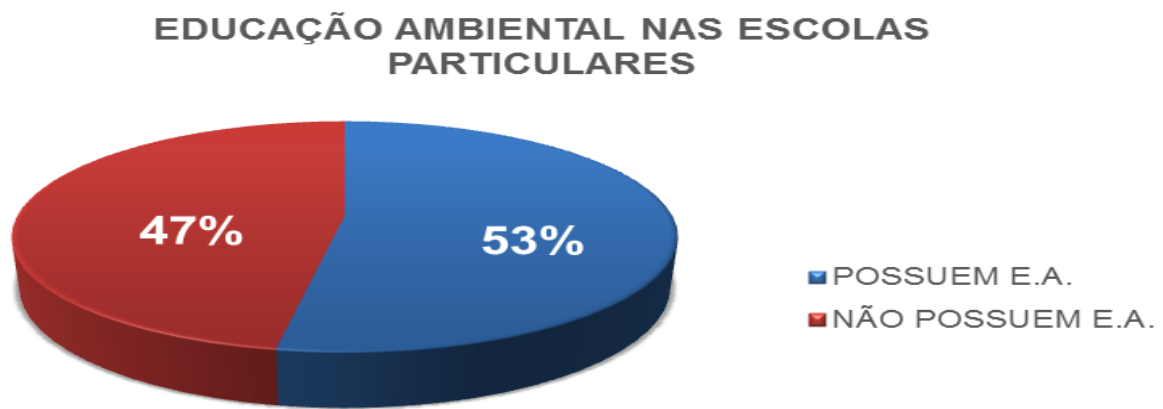

Fonte: A própria autora. 
Nas escolas particulares nota-se um leve equilíbrio quanto a existência da educação ambiental, apesar de serem estabelecimentos de ensino onde é necessário pagar pelas atividades prestadas é evidente que temáticas ambientais não são parte principal do cotidiano escolar. Este fato talvez ocorra pela falta de implantação de atividades que fogem do espaço sala de aula, ou seja, a realização de eventos que utilizem ferramentas da educação informal e não formal. Para um processo de formação educacional ambiental adequado de acordo com a Conferência de Tbilisi (1977), deve-se construir um processo contínuo e permanente da Educação ambiental em todos os níveis de ensino através do ensino formal e não formal e que este deve ser abrangente e extrapolar as atividades internas da escola tradicional, envolvendo a família e coletividade. Segundo Ribeiro (2001), a elevação do grau de consciência, a finalidade imediata da educação, muitas vezes não é cumprida. Entretanto, o fato de ser evidenciada a falta da temática ambiental nestas escolas aponta uma oportunidade para professores e alunos começarem a trabalhar em conjunto a fim de mudar essa realidade. Cabe ressaltar as escolas que realizam atividades ambientais. Um estudo realizado por Silva e Melo (2007) apontou que as principais atividades de E.A. realizadas em escolas particulares eram Coleta Seletiva, Feira de Ciências e Palestras Educativas, sendo estas atividades observadas em sua maioria somente nas datas comemorativas.

Este estudo identificou a Coleta Seletiva, Reciclagem e Participação na Semana do Meio Ambiente como as principais atividades ambientais realizadas pelas escolas particulares. Quando comparado com as práticas ambientais descritas em 2007 por Silva e Melo nota-se a preocupação não somente em separar adequadamente os resíduos, mas também em agregar valor a estes. Identifica-se então um processo de transformação do pensamento levando em consideração a realidade local e a necessidade de mudança da situação.

$\mathrm{Na}$ rede pública estadual de ensino apontada no Gráfico 3 temos um total de 110 escolas analisadas, sendo que 55 escolas afirmam possuir educação ambiental (50\%) e 55 escolas alegam não possuir educação ambiental (50\%).

Gráfico 3: Escolas estaduais que possuem e não possuem educação ambiental EDUCAÇÃO AMBIENTAL NAS ESCOLAS ESTADUAIS

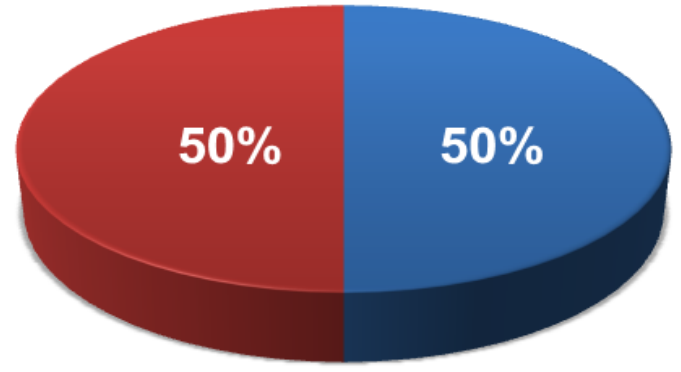

Fonte: A própria autora. 
Nota-se um equilíbrio entre as partes que possuem e não possuem educação ambiental. Pode-se dizer que há uma preocupação por parte do governo estadual em incentivar a educação ambiental nas escolas, porém ainda tem-se um grande déficit em relação à adesão dessas atividades. Sabese que no calendário escolar ocorre a semana do Meio ambiente onde são promovidas atividades relacionadas a atividades ambientais. No entanto, $50 \%$ das escolas avaliadas não consideram esse tipo de atividade como educação ambiental ou não realizam as atividades. Não se sabe ao certo o que priva essas instituições de ensino de realizar adequadamente as atividades ditadas no calendário acadêmico. Entretanto, é conhecido que as atividades devem ser regulares para que o conhecimento obtido possa ser compartilhado entre alunos, professores e comunidade. Segundo Reigota (2009), as práticas ambientais devem deixar de ser esporádicas ou realizadas somente em datas específicas, é preciso incluí-las no dia a dia dos discentes, e relaciona-las e pratica-las nas mais diversas disciplinas.

Em contrapartida, as escolas que afirmaram possuir Educação Ambiental têm a Coleta Seletiva, Reciclagem e Projeto Eureka (projeto do Governo do Estado que tem o objetivo de difundir as ciências nas escolas e transformar as salas de aula em laboratórios) como as principais atividades realizadas na promoção da E.A. Um artigo publicado em 2009 por SilvaFosberg, Mendes e Almeida já descrevia o poder de transformação que projetos ambientais podem ter nas escolas estaduais de Manaus e como podem influenciar os alunos quanto à percepção de sua realidade e quanto aos agentes essenciais do processo de mudança.

O Gráfico 4 mostra a educação ambiental promovida nas escolas públicas municipais totalizando 82 escolas avaliadas sendo que 59 escolas possuem educação ambiental e 23 não possuem.

Gráfico 4: Escolas municipais que possuem e não possuem educação ambiental EDUCAÇÃO AMBIENTAL NAS ESCOLAS MUNICIPAIS

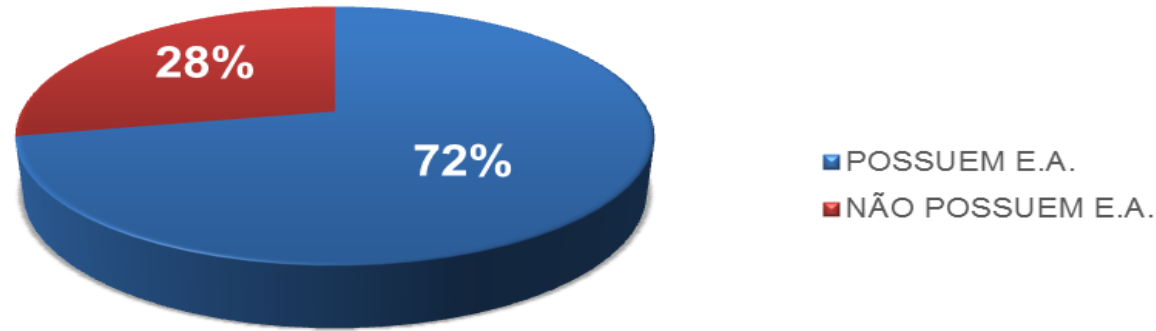

Fonte: A própria autora. 
da Agenda Ambiental pela Prefeitura de Manaus. Segundo a Secretaria Municipal de Educação (SEMED, 2009),

a educação ambiental formal é articulada e disseminada por meio da Agenda Ambiental Escolar, que visa o desenvolvimento sustentável da realidade local de cada escola seguindo as diretrizes da Agenda 21[...]. Além de disseminar educação ambiental não formal (projetos), com suas diversas parcerias. (SEMED, 2009).

De acordo com França e Guimarães (2014, p. 3137), "[...] os projetos e as ações de educação ambiental nas Escolas Municipais de Manaus trazem resultados significativos que promovem mudanças de comportamento $e$ despertam no estudante certo interesse para encontrar soluções para as problemáticas ambientais [...]". Essa afirmação e os resultados mostrados neste estudo corroboram que as ações por parte da Administração Municipal têm surtido efeito positivo na percepção da realidade local.

A respeito de $28 \%$ das escolas que não possuem educação ambiental na rede pública municipal pode-se sugerir que não possuam estrutura adequada para realização das atividades ou não realizem parceria com agências de fomento ou instituições privadas para desenvolvimento das atividades. Segundo um dos princípios da Conferência de Tbilisi (1977), "[...] é preciso insistir no valor e na necessidade de cooperação local, nacional e internacional, para prevenir e resolver os problemas ambientais [...]". Apesar dos resultados apontarem melhoras quanto à preocupação com a educação ambiental, é importante frisar que é de responsabilidade de todos os cuidados com o meio ambiente e a participação da comunidade de entorno e da família é primordial para o sucesso e longevidade das práticas ambientais.

\section{Conclusão}

Ficou evidenciado que infelizmente muitas instituições de ensino encontram-se sem projetos e/ou propostas relativas às atividades ambientais. Isso mostra que ainda participamos de um fraco processo de inclusão ambiental em escolas, apesar de todas as leis e decretos instituídos em nossa Constituição e Programas de governo.

Porém, nota-se um crescente esforço em integrar a educação ambiental no processo de formação dos alunos, a fim de torna-los capazes de interferir positivamente a favor do meio que os cercam.

Contudo, é evidente que se necessita de empenho por parte dos governos, instituições de ensino e amparo e da sociedade, pois o meio ambiente não depende somente dos alunos que estão em desenvolvimento escolar, mas também de todos que nele estão inseridos. Por este motivo, fazse de suma importância à integralização de todos para que seja construído um ambiente promissor e sustentável agora e para as futuras gerações. 


\section{Referências}

BRASIL. Constituição (1988). Constituição da República Federativa do Brasil. (promulgada em 5 de outubro de 1988). Organizador do texto: Juarez de Oliveira. $16^{\circ}$ ed. São Paulo: Saraiva, 1997. Capítulo VI. Arto 225. (Série Legislação Brasileira).

BRASIL. Ministério do Meio Ambiente. Secretaria de Articulação Institucional e Cidadania Ambiental. Departamento de Educação Ambiental. Os diferentes matizes da Educação Ambiental no Brasil: 1997-2007, pág. 192 - 193 Brasília, DF: MMA, 2008. (Série Desafios da Educação Ambiental). Disponível em:<http://www.mma.gov.br/estruturas/educamb/ publicacao/20 publicacao04 062009105709.pdf >, acesso em 16 de novembro de 2014.

BRASIL. Lei n`9.795, de 27 de abril de 1999. Dispõe sobre a Educação Ambiental, institui a Política Nacional de Educação Ambiental e dá outras providências.

Disponível em:<http://www.planalto.gov.br/ccivil 03/leis/l9795.htm>, acesso em 16 de novembro de 2014.

FRANÇA, P.; GUIMARÃES, M. A educação ambiental nas escolas municipais de Manaus (AM): Um estudo de caso a partir da percepção dos discentes. Revista do Centro de Ciências Naturais e Exatas-UFSM, Santa Maria. Revista de Monografias Ambientais - REMOA. V.14, N.2, 2014, p. 3128-3138. Disponível em : $\quad<$ http://cascavel.ufsm.br/revistas/ojs2.2.2/index.php/remoa/article/view/12020>, acesso em 29 de abril de 2014.

GOVERNO DO ESTADO DO AMAZONAS. Dados demográficos do Amazonas. Disponível em: <http://www.amazonas.am.gov.br/oamazonas/dados/ >, acesso em 08 de junho de 2014.

IBGE. Áreas de Ponderação-Manaus (Censo 2010). Disponível em: $<$ http://www.censo2010.ibge.gov.br/apps/areaponderacao/index.html>, acesso em 11 de outubro de 2014.

IBGE. Educação-Manaus (Censo 2010). Disponível em: $<$ http://www.censo2010.ibge.gov.br/apps/mapa/>, acesso em 11 de outubro de 2014.

MARCATTO, C. Educação ambiental: conceitos e princípios. Pág. 21. Belo Horizonte: $\quad 2002 . \quad$ DEAM. Disponível em: $<$ http://www.feam.br/images/stories/arquivos/Educacao Ambiental Conceitos Principios.pdf>, acesso em 23 de março de 2014.

MEDINA, N.M. A formação dos professores em Educação Ambiental. In: Panorama da Educação Ambiental no ensino fundamental / Secretaria de Educação Fundamental. Brasília: MEC; SEF, 2001.

MICROSOFT. Introdução ao Excel 2010. Disponível em: <https://support.office.com/pt-br/article/Introdu\%C3\%A7\%C3\%A30-ao-Excel2010-D8708FF8-2FBD-4D1E-8BBB-5DE3556210F7?ui=pt-BR\&rs=ptBR\&ad=BR> , acesso em 08 de junho de 2014. 
REIGOTA, M. O que é educação ambiental. São Paulo: Brasiliense, 2009.

RIBEIRO, M.L.S. Educação Escolar: que prática é essa? Campinas: Autores Associados, 2001.

SEDUC. Dados Educacionais Amazonas. Disponível em: $<$ http://www.educacao.am.gov.br/seduc-em-numeros/sadeam/>, acesso em 08 de junho de 2014.

SEMED. Escolas, CMEIS e Creches: Cadastro escolar de 2014. Disponível em: < http://semed.manaus.am.gov.br/escolas-cmeis-e-creches/ >, acesso em 11 de outubro de 2014.

SEMED. Educação Ambiental. Disponível em: $<$ http://educacaoambiental.manaus.am.gov.br/educacao-ambiental/>, acesso em 12 de outubro de 2014.

SILVA-FOSBERG, M.C.; MENDES, G.C.; ALMEIDA, A. Educação Ambiental em Escolas Públicas de Manaus, AM: Projetos Integrados Fazem Diferença? Anais do VII Encontro Nacional de Pesquisa em Educação em Ciências. Florianópolis-2009.

SILVA, L.R.; MELO, L.B. Educação Ambiental na Escola: Percepção e Prática de Alunos de Duas Escolas de Ensino Médio da Cidade de Manaus. Revista Igapó, 2007.

UNESCO - ORGANIZAÇÃO DAS NAÇÕES UNIDAS PARA A EDUCAÇÃO, A CIÊNCIA E A CULTURA. Carta de Belgrado, 1975. Disponível em:<http://www.mma.gov.br/port/sdi/ea/deds/pdfs/crt belgrado.pdf>, acesso em 16 de novembro de 2014. 